\title{
Point of View: The importance of Leadership towards universal health coverage in Low Income Countries
}

\section{A Gonani ${ }^{1}$ and AS. Muula ${ }^{2}$}

1. Hospital Director, Queen Elizabeth Central Hospital,

Blantyre, Malawi

2. Department of Public Health, School of Public Health, University of Malawi, College of Medicine, Blantyre, Malawi

\begin{abstract}
Universal health coverage-defined as access to the full range of the most appropriate health care and technology for all people at the lowest possible price or with social health protection - was the goal of the 1978 Alma-Ata Conference on Primary Health Care in Kazakhstan. Many low-income (developing) countries are currently unable to reach this goal despite having articulated the same in their health-related documents. In this paper we argue that, over 30 years on, inadequate political and technical leadership has prevented the realization of universal health coverage in low-income countries.
\end{abstract}

\section{Introduction}

The implementation of universal health coverage has been advocated for since the landmark 1978 Alma-Ata International Conference on Primary Health Care in Kazakhstan in the then Soviet Union ${ }^{1,2}$. Universal health coverage has been defined as access to the full range of the most appropriate health care and technology for all people at the lowest possible price or with social health protection ${ }^{2,3}$. Over thirty after the Alma-Ata conference, progress among low-income countries has been varied and sluggish at best. For instance, only $40 \%$ of the population in Namibia and $50 \%$ of Zambia lived within $5 \mathrm{~km}$ from a health facility in $2008^{4,5}$. The Malawi Poverty Reduction Strategy Paper of 2002 reported that "physical access to health centres has remained poor, with only $3 \%$ of the population living in a village with a health centre" . According to McCoy et al (2005), about $46 \%$ of the population in Malawi had access to a formal health facility within a $5 \mathrm{~km}$ radius, while $20 \%$ lived within $25 \mathrm{~km}$ of a hospital ${ }^{6}$. A 2006 service satisfaction survey in Malawi established that on average, people had to travel over $10 \mathrm{~km}$ to reach the nearest public health centre and the distance to a district hospital, which is the primary referral center, was about $30 \mathrm{~km}^{7}$. A third of the respondents reported travelling on foot to the health facility, with $55 \%$ reporting that it took them over two hours to get there ${ }^{7}$. Senegal's extreme distances to health facilities and poor environmental conditions, mean that only about $32 \%$ of rural households have regular access to a health centre; walking is also the major mode of transport there ${ }^{8}$. The situation is similar to the one in an urban region of South Africa, where over $43 \%$ of community health centre attendees reported walking to the facility and about $55 \%$ of them travelling over $5 \mathrm{~km}^{9}$. In these environments, where the common mode of transport to a health facility is walking, geographical distance-which may not be a concern in high income countries with developed transport systems - can be a major barrier to accessing health care. In addition, it has long been established that user fees have a negative effect on equity of access through reduction of usage of health services $^{10}$. In Sudan, $70 \%$ of the population in disadvantaged areas do not seek care when ill due to poverty ${ }^{1,10}$. A 2002 study in Mozambique reported that $52 \%$ of rural patients found it difficult to find money to pay user fees to the extent that $20 \%$ of them had to borrow the money and $17 \%$ had to sell their assets ${ }^{11}$. Furthermore, the coverage of some preventive services in many places has not yet reached a level to have a significant positive impact on public health; for example the coverage of under-five children sleeping under insecticide-treated bed nets was merely $9.7 \%, 22.8 \%$, and 23\% in Uganda, Zambia and Malawi respectively in $2006^{12}$. Several reasons have been suggested to explain this poor dispensation, summed up as weak health systems, ${ }^{13}$ aggravated by inadequate expenditure on health ${ }^{14}$ and a shortage of human resources for health ${ }^{15}$. We contend, however, that the root cause is inadequate leadership to oversee the gradual and systematic roll-out of universal health coverage in low-income countries.

\section{Inadequate political and technical leadership}

While acknowledging that the cause of the inadequate implementation of universal coverage is multi-factorial, we argue that the root cause is inadequate political and technical leadership. Not enough visionary, innovative, decisive, ${ }^{16}$ responsible and responsive, transparent, exemplary and inspirational leadership is being displayed to influence all stakeholders to work together to achieve the constructive purpose of universal coverage in low-income countries. Regardless of the existing status of health systems and resources in these countries, effective leadership would form a clear national vision towards universal coverage and commit to meeting this vision gradually over time thereby measurably moving towards achieving it. We propose that such leadership has not been consistently and sustainably displayed since the 1978 Alma-Ata conference.

\section{Political Leadership}

Political leadership towards universal health coverage is the prerequisite that is often taken for granted in low-income countries. To be implemented, universal coverage has first to be embraced as a political goal ${ }^{1}$. It was through bold political leadership that Thailand adopted their universal coverage policy in 2001 and Zambia abolished user fees in rural areas in $2006^{14}$. Political leadership has also been credited with the reduction in both HIV prevalence and incidence in Uganda ${ }^{17}$. In all these instances the political leadership emanated from the highest political office, i.e., the presidency. Indeed, presidential leadership facilitates collaboration across an entire government and pressures all stakeholders to deliver successful outcomes ${ }^{11}$. Genuine and sustainable political leadership should seek to legally institutionalize universal health coverage; after all, if health is a basic human right as declared by the Alma-Ata conference and other international treaties, ${ }^{2,18}$ why should it not be enshrined in national constitutions? We argue that it was not by chance that as recent as 2008, only 34\% of 183 countries' constitutions or bills of rights globally recognized the right to health despite all of them having ratified international treaties on the same ${ }^{8}$. Constitutional recognition of health as a human right that is enjoyed through universal coverage would make universal health coverage a legal obligation and hopefully a prominent priority in the political arena. In such a situation, in a democratic dispensation, politicians would compete on who could provide the best model while seeking office. 
Competing political positions on universal coverage should be made explicit in political party policies and marketed to the public as is the case in some high-income countries, ${ }^{19}$ so that failure to implement the promise should breed pressure from parliaments, civil society, human rights institutions, activists, courts ${ }^{18}$, and the citizenry.

\section{Technical Leadership}

The political leadership has to be matched by technical leadership at all levels of the national health system. In order to effectively provide a holistic strategic vision towards universal coverage, low-income countries' health systems require technical leaders who understand health as a human right and are technically competent. These technical leaders must be appointed to positions transparently and on merit, based on academic and professional qualifications and relevant experience, rather than solely because of political considerations $^{2,16}$. Quality technical leadership will seek to understand the existing status of national health systems and constraints that are preventing them from moving towards universal coverage through conducting participatory and comprehensive situation analyses ${ }^{18}$. The results should be used to holistically appraise national health policies, plans and guidelines so that they reflect the national universal health coverage vision ${ }^{1}$. As obvious as this crucial step seems, the evidence shows the contrary: in 2008, a global survey found that $48 \%$ of 29 mostly developing countries did not have explicit commitment to universal coverage in their national health plans ${ }^{18}$.

\section{An Essential Health Package}

Having updated the national health policies, further technical leadership is required to conceive an essential health package composed of interventions targeting the preventive and curative aspects of the most burdensome diseases and conditions and their underlying determinants. An essential health package should be based on local epidemiology, resource availability, cost effectiveness, feasibility and equity, among other explicit criteria ${ }^{1}$. Such a package should be guaranteed for universal coverage as called for by the AlmaAta conference ${ }^{2}$. Unfortunately, the reality is that often the availability or lack of donor support plays a major role in the choice of interventions to implement ${ }^{13}$. This pitfall should be avoided as overreliance on donor funding reduces ownership, flexibility and sustainability ${ }^{13}$.

\section{Strategic plan}

A multi-year national health sector strategic plan should be formulated outlining the implementation of the essential health package, progressively defining an increasing scope and complexity of service coverage matched with forecasted resources and monitoring indicator ${ }^{\mathrm{s} 1,18}$ This should be followed by compiling national and subnational implementation plans, such as district or facility implementation plans and monitoring frameworks ${ }^{20}$ to actualize the strategic plan. Essentially, all levels of the national health system should plan for and forecast their resource needs and formulate resource mobilization strategies towards this initiative ${ }^{1}$. The question that could be asked is: how many developing countries objectively forecast the full range of resource needs of gradually going to scale with interventions, taking into account the intervention's specifications, expected quality, delivery strategies, target population, service provider mix and the coverage to be achieved $^{13}$ ? It is doubtful that many do given the widespread reports of weak health systems, ${ }^{13}$ inadequate funding, ${ }^{14}$ chronic shortage of human resources for health ${ }^{8,9,15}$ and drugs and supplies; $;, 11$ and infrastructure constraints ${ }^{8}$. These are probably signs of either inadequate comprehensive planning and forecasting or technical short-sightedness. Leaders that would comprehensively plan and forecast resources will be systems thinkers; effective collaborators that mobilize sectoral and intersectoral partners, local and international stakeholders to share the vision; and own the process of moving towards universal coverage ${ }^{1}$. Clearly such leadership should start with the public sector technocrats being stewards of national health systems; and given that, universal coverage relies on a robust public health system ${ }^{21,22}$.

\section{Inadequate commitment}

Political rhetoric, technical vision and plans alone are not enough to achieve universal coverage; they have to be complemented with sustained political and technical commitment to translate the plans into actions. Devoid of commitment, it is not uncommon that excellent policy documents and plans only end up on bookshelves to gather dust.

\section{Political commitment}

Political commitment towards universal coverage would singularly be displayed by countries adequately allocating and closely monitoring the use of financial resources to the health sector; for example, African countries meeting the long overdue 15\% Abuja Declaration target of $2001^{23}$. While donors should be urged to meet their development assistance obligations, ideally they should be complementing optimal national efforts to generate funds to avail the national health sector. Ironically, rising development assistance for health to governments has led to a significant reduction of domestic government spending on health in some countries of sub-Saharan Africa, ${ }^{24}$ which is retrogressive. Another example is the 2014-2015 Malawi National Health Budget in which the Malawi Treasury allocated just about half of the Ministry of Health requirements on account that significant shortfalls could be covered by development partners ${ }^{25}$. Since universal coverage has been globally advocated for a long time, we contend that there should be a global consensus that donors or development partners should only earmark additional health aid to countries that are measurably and progressively implementing universal coverage, or at least on the way to doing so ${ }^{10}$. Optimum financial commitments and disbursement from local and international sources to the national health sector should foremost be accompanied by a political monitoring process to check pilferage and corruption to ensure that it is used for the intended purpose. This responsibility primarily rests with the ministers of health, who should themselves be above reproach, to credibly and regularly appraise universal coverage implementation and report to parliaments.

\section{Technical commitment}

Technical commitment will see the implementation of planned universal coverage activities through ensuring that earmarked resources are equitably distributed throughout the health system. For example, among other strategies, formulating a human resources deployment policy that includes an incentive package to ensure that health workers serve rural and underserved areas ${ }^{1}$. The leadership should invest in building capacity for leadership, management and supervision at all level of the national health system to 
effectively and efficiently manage the resources. Leaders should seek to form partnerships with communities, the private sector, non-governmental organizations and intersectoral partners to fill resource and service delivery gaps, resulting in efficiency savings and greater accessibility in rural and underserved areas ${ }^{13,21}$. Service delivery strategies emanating from these partnerships should be rigorously reviewed for cost-effectiveness and socio-cultural acceptability in addition to assuring quality of delivery ${ }^{13}$.

\section{Monitoring}

To effectively monitor the implementation of universal health coverage, technical leadership should strive to establish or strengthen existing routine monitoring systems into a single integrated national system that takes into consideration stakeholder data needs. There should be generation of timely, reliable and publicly accessible data that should, above all, be used ${ }^{26,27}$. Empirical evidence suggests that routine health data is usually incomplete, inadequately used locally for decision making and is untimely reported to the next level in Malawi, Tanzania and Uganda ${ }^{28}$. Practical steps have to be taken to counter this tendecy if planned universal coverage targets will be effectively monitored. As a way of promoting transparency, accountability and ownership, a participatory institutionalized process of regular quarterly, mid-year and annual health sector reviews of operational plans from the sub-national to the national level, culminating into the formulation of joint actionable recommendations should be instituted to monitor progress ${ }^{26,27}$. It is encouraging that a number of African countries including Ethiopia, Kenya, Lesotho, Malawi, Tanzania, Uganda and Zambia are carrying out regular periodic health sector reviews, mostly influenced by Sector-Wide Approaches ${ }^{26}$.

\section{Operational research and evaluation}

The technical leaders should also plan for and provide a conducive environment for operational and health systems research to inform the optimization of the planning and service delivery process. They should also commission independent evaluation of the national strategic plan to determine whether objectives are being met for the lessons to inform the development of the next $\operatorname{plan}^{27}$. While the conduct of mid-term and final evaluations of national strategic plans is coming up in some African countries under the influence of Sector Wide Approaches, ${ }^{26}$ the capacity and resources to carry out operational research are mostly lacking in low-income countries ${ }^{29}$. It is time to build local research agendas and capacity into universal coverage interventions if we are to enhance the quality and effectiveness of these interventions, and meet coverage targets ${ }^{29}$. Evidence from research and evaluation together with the routine data, if accessible to advocacy and other interest groups, is a basis for holding political and technical leaders accountable as well as sensitizing populations to demand health care services. Most importantly, leaders should take personal responsibility for the successful implementation of universal health coverage. Technical leaders at all levels should be formally held accountable for meeting planned targets through the institution of robust performance appraisal systems.

\section{Conclusion}

We contend that regardless of a low-income nation's state of health system and resources, political and technical leadership and commitment are prerequisite toward progressively realizing universal health coverage. Leadership can formulate a clear national vision, and leadership can comprehensively plan and progressively commit resources and measurably implement activities towards universal coverage. Ultimately achieving universal health coverage is a question of focus and incrementally doing the best with what the particular low-income country already has at a given time. To renew the focus calls for national soul-searching. Low-income countries should conduct objective in-depth reviews of their national health systems in order to understand and learn from the political and technical leadership constraints preventing them from moving earnestly towards universal health coverage.

\section{References}

1.World Health Organization. The World Health Report 2008: Primary Health Care - Now more than ever. World Health Organization. Geneva : WHO 2008.

2. World Health Organization. Declaration of Alma-Ata: International Conference on Primary Health Care, Alma-Ata, USSR, 6-12 September 1978. Accessed 30 June 2010 from: http://www.who.int/hpr/NPH/docs/ declaration_almaata.pdf.

3. Institute of Tropical Medicine. Emerging Voices. Institute of Tropical Medicine 52nd Annual Colloquium. Accessed 20 June 2010 from http:// www.itg.be/internet/colloq2010/index.htmhttp://www.itg.be/internet/ colloq2010/essay\%20competition.html.

4. Ministry of Health and Social Services Namibia. Health and Social Services System Review. Ministry of Health and Social Services, The Republic of Namibia, Ministry of Health and Social Services, 2008.

5. Chabot J, Aantjes C, Beks H, et al. Report of the Midterm Review of the Zambia National Health Strategic Plan IV 2006-2010. Lusaka : The Independent Review Team, November 2008.

6. McCoy, D., H. Ashwood-Smith, E. Ratsma, and J. Kemp. Going from bad to worse: Malawi's maternal mortality. Health Systems Trust, South Africa 2005.

7. Malawi Economic Justice Network Service. Delivery Satisfaction Survey III-Delivering the Promises: Making Public Services Accessible To the People. Malawi Economic Justice Network, Lilongwe, Malawi 2006.

8. Heyen-Perschon J. Report on current situation in the health sector of Senegal and possible roles for non-motorised transport interventions. Institute for transportation and development policy website. 2005. Accessed 5th December 2010 from http://www.itdp.org/documents/ ITDP\%20Transport $\% 20$ and $\% 20$ Health $\% 20$ Care $\% 20-\% 20$ Senegal.pdf

9. Nteta TP, Mokgatle-Nthabu M, Oguntibeju O. Utilization of the Primary Health Care Services in the Tshwane Region of Gauteng Province, South Africa. PLoS ONE. 2010 5(11): e13909.

10. Yates R. Universal health care and the removal of user fees. Lancet 2009; 373: 2078-81.

11.Yates R. International Experiences in Removing User Fees for Health Services - Implications for Mozambique. DFID Health Resource Centre. 2006. Accessed 5th December 2010 from http://www. dfidhealthrc.org/publications/health_sector_financing/06Yates01.pdf

12. United Nations. Millenium Development Goals Indicators: The official United Nations site for the MDG indicators. United NationsUnited Nations, 14 July 2009. Accesed on August 2009 from: http://mdgs.un.org/unsd/mdg/Data.aspx.

13. Victora C, Hanson K, Bryce J, Vaughan J. Achieving universal coverage with health interventions. Lancet 2004; 364:1541-48.

14. Guy C, Mathauer I, Xu K, Evans D. Universal coverage of health services: tailoring its implementation. Bulletin of the World Health Organization 2008; 86 
15. Hanson K, Cleary S, Schneider H, Tantivess S, Gilson L. Scaling up health policies and servives in low and middle income setting. BMC Health Services Research 2010; 10.

16. Harries A, Schouten E, Ben-Smith A, et al. Health Leadership in sub-Sahara Africa. : Tropical Doctor 2009 ; 39:193-95.

17. Parkhurst JO, Lush L. The political environment of HIV: lessons from a comparison of Uganda and South Africa. Soc Sci Med 2004; 59: 1913-24.

18. Backman G, Hunt P, Khosla R, et al. Health systems and the right to health: An assessment of 194 countries. Lancet 2008; 372:2047-85.

19. Zwillich T. The US presidential hopeful's health policies. Lancet 2008; 371: 885-88.

20. World Health Organization. Ouagadougou Declaration on Primary Health Care and health systems in Africa: achieving better health for Africa in the new millennium. World Health Organization. Accesed 06 July 2009 from: http://www.afro.who.int/phc_hs_2008/documents/En/ Ouagadougou\%20declaration\%20version\%20Eng.pdf.

21. Lancet Editorial. Universal health coverage: access to what? Lancet 2009; 374:1946.

22. World Health Organization. The World Heath Report 2000: Health Systems - Improving Performance. WHO, 2000.

23. Organization of African Unity. Abuja Declaration on HIV/AIDS, Tuberculosis and other related infectious diseases. United Nations. Accessed on 26 August 2009 from: http:/www.un.org/ga/aids/pdf/ abuja_declaration.pdf.
24. Lu C, Schneider M, Gubbins P, Leach-Kemon K, Jamison D, Murray C. Public financing of health in developing countries: a crossnational systematic analysis. Lancet 2010; 375: 1375-87.

25. Minister of Finance and Economic Development. Budget Statement on the Malawi National Assemby on the 2014-2015 National Budget, September, Lilongwe, Malawi, 2014

26.World Health Organization. Implementing Periodic Health Sector Reviews in Nine Sub-Sahara African Countries Review Report - A Working Document. Intercountry Support Team for the East and Southern Africa, WHO-AFRO. Harare : WHO, 2009. Working Document.

27. De Brouwere V. Public Health: Management and Evaluation of Health Programmes. Antwerp : Institute of Tropical Medicine, 2008.

28. Gonani, A. Assessment of the District Monitoring and Evaluation System focusing on Disease Control in Northern Malawi. Institute of Tropical Medicine. Antwerp, Belgium: Institute of Tropical Medicine, 2008. Masters of Public Health Thesis.

29. Zachariah R, Harries A, Ishikawa N, et al. Operational research in low-income countries: what, why, and how? Lancet Infect Dis 2009; 9: $711-17$ 